\title{
Improving early exclusion of acute coronary syndrome in primary care: the added value of point-of-care troponin as stated by general practitioners
}

\author{
Michelle M.A. Kip ${ }^{1}$, Amber M. Noltes ${ }^{1}$, Hendrik Koffijberg ${ }^{1}$, Maarten J. IJzerman ${ }^{1}$ and Ron Kusters ${ }^{1,2}$ \\ ${ }^{1}$ Department of Health Technology and Services Research, MIRA institute for Biomedical Technology and Technical \\ Medicine, University of Twente, Enschede, The Netherlands \\ ${ }^{2}$ Laboratory for Clinical Chemistry and Haematology, Jeroen Bosch Ziekenhuis, Den Bosch, The Netherlands
}

\begin{abstract}
Aim: To investigate general practitioners' (GPs') desire and perceived added value of point-of-care (POC) troponin, its effect on referral decisions, and test requirements. Background: Excluding acute coronary syndrome (ACS) in primary care remains a diagnostic challenges for GPs. Consequently, referral rates of chest pain patients are high, while the incidence of a cardiovascular problem is only $8-15 \%$. Previous studies have shown that GPs are interested in a POC troponin test. This test could enhance rapid exclusion of ACS, thereby preventing unnecessary patient distress, without compromising safety and while reducing costs. However, using this test is not recommended in current guidelines due to uncertainty in the test's potential added value, and the lower sensitivity early after symptom onset as compared with troponin tests in a regular laboratory. Methods: An online survey containing 34 questions was distributed among 837 Dutch GPs in June 2015. Findings: A total of 126 GPs (15.1\%) completed at least $75 \%$ of the questions. $67.1 \%$ of GPs believe that POC troponin tests have moderate to very high added value. Although the availability of a POC test is expected to increase the frequency at which troponin tests are used, it likely decreases (immediate) referral rates. Of the responding GPs, $78.3 \%$ only accept $10 \mathrm{~min}$ as the maximum test duration, $78.1 \%$ think reimbursement of the POC device is required for implementation, and $68.9 \%$ consider it necessary that it can be performed with a finger prick blood sample. In conclusion, according to GPs, the POC troponin test can be of added value to exclude ACS early on. Actual test implementation will depend on test characteristics, including test duration, type of blood sample required, and reimbursement of the analyzer.
\end{abstract}

Key words: acute coronary syndrome; point-of-care systems; primary health care; referral and consultation; surveys and questionnaires; troponin

Received 16 December 2016; revised 6 February 2017; accepted 12 February 2017;

first published online 2 May 2017

\section{Background}

Coronary heart disease is one of the main causes of mortality. Worldwide, it accounted for about 7.4 million deaths in 2012 (World Health

Correspondence to: Mrs Michelle M.A. Kip, MSc., Department of Health Technology and Services Research, MIRA Institute, University of Twente, P.O. Box 217, 7500 AE Enschede, The Netherlands. Email: m.m.a.kip@utwente.nl
Organization, 2016). Acute coronary syndrome (ACS) is one of the main manifestations of coronary heart disease, with chest pain as a leading symptom. As ACS encompasses unstable angina pectoris and acute myocardial infarction (AMI), rapid diagnosis or exclusion of ACS is crucial to allow initiation of effective evidence-based treatment and management (Authors/Task Force Members et al., 2015). As a patient's signs and symptoms alone are often insufficient to rule out 
AMI in general practices (Bruyninckx et al., 2008), $\sim 29 \%$ of all patients presenting with chest pain in the GP's office are immediately referred (Okkes et al., 2005), while the estimated incidence of a cardiovascular problem among those patients is relatively low (8-15\%) (Buntinx et al., 2001; Nilsson et al., 2003; Ruigomez et al., 2006; Bosner et al., 2009; Rutten et al., 2012). This suggests that between six out of seven and 11 out of 12 patients are referred to the hospital without having ACS. Those unnecessary hospital referrals will incur patient distress as well as high healthcare costs. In general, the aging population and the increasing number of patients with multiple (chronic) conditions, have led to an increase in healthcare usage, and consequently to rising healthcare costs (Wiener and Tilly, 2002). Therefore, GPs are increasingly pressured to play a gatekeeping role in the healthcare system to reduce referrals from primary to secondary care. Because of the high referral rate among chest pain patients, there is large potential for improvement regarding the exclusion of ACS in primary care.

To guide their referral decision, GPs can order a troponin test at a regular laboratory to detect myocardial injury or necrosis (Thygesen et al., 2012; Authors/Task Force Members et al., 2015). Currently available high-sensitive troponin tests have increased the diagnostic accuracy for AMI as compared with conventional assays, especially in patients presenting early after chest pain onset (Authors/Task Force Members et al., 2015). Although point-of-care (POC) tests for troponin have become available, the majority of those tests are less sensitive than the currently available laboratory troponin tests. Consequently, POC troponin tests may not be able to detect a small rise in a patient's troponin level very early after the onset of an AMI, indicating that those tests cannot be used for diagnosing AMI with certainty in the early hours after symptom onset (Bruins Slot et al., 2013; Authors/Task Force Members et al., 2015). Nevertheless, previous research has shown that a POC troponin test might be of added value in excluding ACS in low-risk patients presenting at the GP with a longer duration of symptoms or whose symptoms have already resolved (Tomonaga et al., 2011; Marshall et al., 2014).

Recently, an international survey study by Howick et al. (2014) found that $66 \%$ of GPs in five countries, including the Netherlands, the United States, the United Kingdom, Australia, and Belgium, would like to have access to a POC troponin test (Howick et al., 2014). However, there may be a mismatch between anticipated benefits (improving general practitioners' (GPs') ability to rule out ACS) and actual test performance. Furthermore, current Dutch guidelines discourage the use of a POC test to rule out ACS in general practices, while international guidelines do not give a recommendation on whether or not to use the POC troponin test in those patients (Dutch College of General Practitioners, 2012; Authors/Task Force Members et al. 2015). Despite the issues with the limited diagnostic performance of this POC test, more sensitive POC troponin tests are currently being developed (Philips In-vitro Diagnostics, 2016). As those developments may allow safe use of this test in the nearby future, they might enhance GPs' ability to safely exclude and even diagnose ACS in primary care. However, it is likely that the decision whether or not to implement this test will not solely depend on its diagnostic performance. Therefore, early insights in additional barriers and facilitators regarding implementation of this test, the expected use of this test in clinical practice, as well as the impact on referral decisions, may help both test developers and clinicians in providing safe and efficient healthcare. In turn, this likely facilitates rapid and efficient implementation as soon as those more sensitive tests become available. Therefore, this study aims to investigate a broad range of GPs' preferences and requirements regarding POC troponin testing for patients presenting with chest pain in primary care, as well as its effect on GPs' referral decisions.

\section{Methods}

A survey was constructed in LimeSurvey (LimeSurvey Project Team/Schmitz, 2015) to identify GPs' opinions and requirements concerning the use of POC troponin testing in chest pain patients, and the indicated impact on GPs' referral decisions. Qualitative interviews with ten GPs served as input for the design of this survey, by providing insight into the GP's diagnostic process and decision making in patients presenting during consultation hours with chest pain in Dutch primary care. Following this, the survey was tested in a pilot study with four GPs to evaluate feasibility and completeness. The final survey (in Dutch) consisted of 34 questions, divided in five elements. 
The first element included seven questions concerning general information about the GPs (eg, age, gender, years of working experience, type of general practice). The second element (seven questions) was about current practice, including the distance to the nearest hospital and coronary intervention center, estimated referral rates of new hypothetical chest pain patients to the hospital, the role of GPs' gut feeling in this decision, the percentage of patients presenting with symptoms for $\geqslant 6 \mathrm{~h}$, and about the different POC tests that are currently available in their general practice. The third element contained seven questions about: the expected added value of the POC troponin test, the frequency at which they estimate to currently order laboratory troponin tests in chest pain patients, the frequency at which they expect to perform POC troponin tests for this purpose, and the aspects favorably affected by implementation of this test. In this question, GPs were asked to choose all applicable answers from a predefined list, based on a study by Cals et al. (2014) which was slightly adapted to the use of a POC troponin test (the aspect 'diagnostic speed' was added, while aspects concerning medication use and therapy compliance were removed) (Cals et al., 2014). The fourth element (10 questions) concerned the effect of a POC troponin test on GPs' referral rates using two hypothetical patient cases, which were designed to represent one low and one intermediate risk case of ACS (based on known risk factors but without actual prediction of their ACS risk). For both cases, GPs were given the patient's signs, symptoms, medical history, medication use, and vital functions. For each case, GPs were asked if they would immediately refer this patient to the hospital, refer the patient for an appointment at an outpatient cardiology clinic, not refer the patient (indicating that no action is taken), or decide otherwise (open answer). GPs who decided to refer immediately were asked to additionally consider a negative POC troponin test result, which could have been available for this patient during consultation. They were asked whether this information would make them revise their decision. In contrast, GPs who decided not to refer immediately, were presented with a slightly elevated troponin level and posed the same question. GPs who still decided not to refer immediately were presented with a strongly elevated troponin level and again posed the same question. As cut-off levels for troponin may differ between laboratories, misinterpretation was prevented by mentioning whether the troponin level was either negative, slightly elevated, or strongly elevated. The fifth element contained three questions concerning the maximum acceptable test duration, necessity of reimbursement of the analyzer, and the requirement of performing this test using a finger prick blood sample. The full survey (translated to English) is provided in Additional file 1.

The survey was distributed among 837 Dutch GPs affiliated to one of seven participating GP associations, located in four provinces of the Netherlands (Overijssel, Gelderland, Utrecht, and NoordBrabant). All GPs were invited by email (by A.N., or by the GP association to which they were affiliated) to fill out the survey from Tuesday June 9, 2015 to Wednesday June 24, 2015. After 1 week, a reminder was send out to all non-responders. All responses were processed anonymously.

The representativeness of the responding GPs of the entire population of GPs in the Netherlands was evaluated by comparing the respondents' age and gender to data of GP registrations from the Netherlands Institute for Health Services Research (Nederlands instituut onderzoek van de gezondheidszorg, NIVEL), using the one sample $t$-test and the nonparametric binomial test $(\alpha=0.05)$. To investigate whether the added value of the POC troponin test is considered higher when the distance between the nearest hospital or coronary intervention center increased, this relationship was examined using the $\chi^{2}$ test. A $\chi^{2}$ test was also performed to investigate whether the indicated importance of GP's gut feeling in making a referral decision, affected the extent to which they changed their initial referral decision following a discordant POC troponin test result. Data were analyzed using $\mathrm{R}$ (version 3.2.3). The package mice (version 2.25) was used for multiple imputation of missing data (10 imputation sets) (van Buuren and Groothuis-Oudshoorn, 2011; R Core Team, 2015). Multiple imputation is known to yield more valid results than complete case analysis (van der Heijden et al., 2006). To assess the effect of missing values on our results, estimates from complete case analysis and multiple imputation were compared.

\section{Results}

\section{Characteristics of responding GPs}

In total, 169 GPs $(20.2 \%)$ participated in the survey. Results of 43 respondents were necessarily 
Table 1 Characteristics of participating GPs, and the role of GPs' gut feeling in their referral decision

\begin{tabular}{|c|c|c|}
\hline & $\begin{array}{l}\text { Complete } \\
\text { cases }\end{array}$ & $\begin{array}{l}\text { Multiple } \\
\text { imputation }\end{array}$ \\
\hline Participating GPs [n (\%)] & $115(100.0)$ & $126(100.0)$ \\
\hline Male $[n(\%)]$ & $74(64.3)$ & $80(63.5)$ \\
\hline Age in years [mean (SD)] & $49.0(9.3)$ & $48.4(9.4)$ \\
\hline $\begin{array}{l}\text { Years of working experience as } \\
\text { a GP [mean (SD)] }\end{array}$ & $16.9(9.7)$ & $16.2(9.7)$ \\
\hline $\begin{array}{l}\text { Independent GP (own practice) } \\
{[n(\%)]}\end{array}$ & $98(85.2)$ & 107 (84.9) \\
\hline \multicolumn{3}{|l|}{$\begin{array}{l}\text { Distance to nearest hospital (\%) } \\
(\mathrm{km})\end{array}$} \\
\hline$<2$ & 18.3 & 16.7 \\
\hline $2-5$ & 21.7 & 23.0 \\
\hline $5-10$ & 27.0 & 25.6 \\
\hline $10-20$ & 27.8 & 29.8 \\
\hline $20-40$ & 5.2 & 4.9 \\
\hline$>40$ & 0 & 0 \\
\hline \multicolumn{3}{|l|}{$\begin{array}{l}\text { Distance to nearest coronary } \\
\text { intervention center }(\%)(\mathrm{km})\end{array}$} \\
\hline$<2$ & 9.6 & 8.7 \\
\hline $2-5$ & 14.8 & 15.1 \\
\hline $5-10$ & 16.5 & 15.1 \\
\hline $10-20$ & 26.1 & 25.5 \\
\hline $20-40$ & 28.7 & 31.3 \\
\hline$>40$ & 4.3 & 4.3 \\
\hline \multicolumn{3}{|l|}{$\begin{array}{l}\text { Role of GPs' gut feeling in } \\
\text { immediate referral decision (\%) }\end{array}$} \\
\hline None & 0.0 & 0.0 \\
\hline Barely & 2.6 & 2.4 \\
\hline To a moderate extent & 20.9 & 23.0 \\
\hline To a high extent & 64.3 & 62.7 \\
\hline To a very high extent & 12.2 & 11.9 \\
\hline
\end{tabular}

This table shows the characteristics of the participating GPs, the distance from the general practice to the nearest hospital and to the nearest coronary intervention center, as well as the role of GPs' gut feeling in the decision to immediately refer a patient to the hospital.

excluded because they were either not registered as a GP $(n=6)$ or because they only started the survey but completed less than $25 \%$ of the questions $(n=37)$. Of the remaining 126 GPs (15.1\%), 10 GPs missed one question $(7.9 \%)$, and one GP missed two questions $(0.8 \%)$. They needed $\sim 15 \mathrm{~min}$ to fill out the survey. Given the limited amount of missing values, results from multiple imputation were very similar to the results from complete case analysis (Table 1). Therefore, only results from multiple imputation are reported.

Of the responding GPs, 80 (63.5\%) were male (Table 1$)$, the mean age was 48.4 years $(\mathrm{SD}=9.4)$, the average working experience as GP was
16.2 years $(\mathrm{SD}=9.7)$, and 107 GPs $(84.9 \%)$ had their own general practice. There was no significant difference in mean age between the responding GPs and the NIVEL database $(n=11,345)$ (48.4 versus 48.9 years, $P=0.57)$ (van Hassel et al., 2015). However, a larger proportion of the responding GPs were male, although not statistically significant ( 63.5 versus $55.2 \%, P=0.07$ ). The distance to the nearest hospital was $<20 \mathrm{~km}$ for $95.1 \%$ of GPs, whereas the distance to the nearest coronary intervention center was $<20 \mathrm{~km}$ for $64.4 \%$ (Table 1 ).

\section{Current work-up}

GPs indicated that $54.9 \%(\mathrm{SE}=2.0 \%)$ of all patients presenting with chest pain report symptoms for $\geqslant 6 \mathrm{~h}$. Of all patients presenting with chest pain, GPs estimate to refer $26.8 \%(\mathrm{SE}=2.0 \%)$ immediately to the hospital (Figure 1). Of those immediate referrals, GPs had strong suspicion in $54.7 \%(\mathrm{SE}=2.2 \%)$, were uncertain about the presence of ACS in $33.0 \%$ ( $\mathrm{SE}=1.6 \%$ ), while $12.2 \%(\mathrm{SE}=1.8 \%)$ were referred to reassure the patient (no suspicion of ACS) (Figure 1). A total of $97.6 \%$ of GPs indicate that their gut feeling has moderate, high or very high impact on this decision (Table 1).

\section{GPs' desire to use the POC troponin test and its perceived added value}

In all, $67.1 \%$ of GPs believe that POC troponin tests have moderate, high or very high added value for diagnosing patients with chest pain in general practice (Table 2). Only five GPs $(4.0 \%)$ already had a POC troponin analyzer in their general practice (for details about the availability of POC analyzers in general practices see Additional file 2). Three of those GPs consider this test to have high $(n=1)$ or very high added value $(n=2)$ for diagnosing ACS in general practices, while only one considers this test of barely added value. Furthermore, the perceived added value of this POC test (none, barely or moderate added value, as compared with high or very high added value) was significantly higher for GPs whose practices are situated $\geqslant 10 \mathrm{~km}$ from the nearest hospital $(P=0.01)$, as compared with GPs whose practices are situated closer to the hospital. However, this difference was not significant for the distance from the nearest coronary intervention center $(P=0.16)$. 


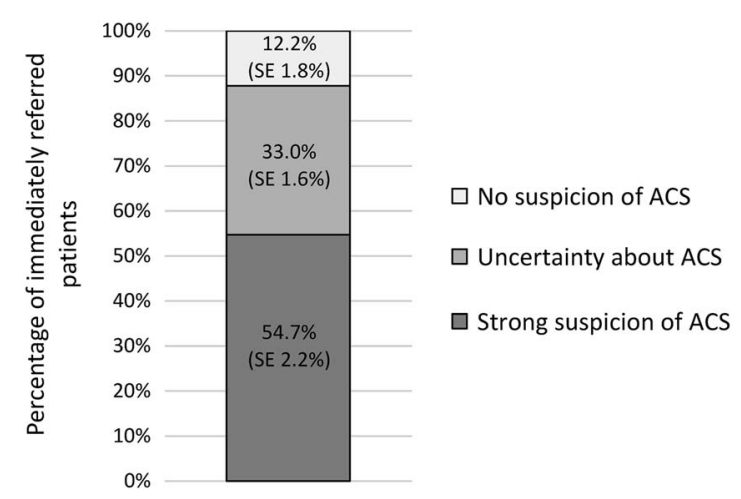

Figure 1 Estimated referral rates. This figure shows the estimated referral rates of patients presenting with chest pain in primary care [26.8\% (SE 2.0\%)] of all patients presenting with chest pain in primary care who are immediately referred to the hospital.

Table 2 Expectations of GPs with regard to the added value of using point-of-care (POC) troponin testing

\begin{tabular}{lr}
\hline Expected added value (\%) & \\
None & 6.3 \\
Barely & 26.5 \\
To a moderate extent & 28.3 \\
To a high extent & 31.7 \\
To a very high extent & 7.1 \\
Aspects favorably affected (\%) & \\
Diagnostic certainty & 67.5 \\
Diagnostic speed & 55.6 \\
Patient safety & 42.1 \\
Healthcare costs & 41.3 \\
Patient satisfaction & 31.7 \\
Substitution to primary care & 30.2 \\
Doctor-patient relationship & 21.4 \\
Work satisfaction & 19.0 \\
Doctor-patient communication & 14.3 \\
Other & 0.8 \\
None of the above & 12.7 \\
\hline
\end{tabular}

This table shows the expected added value, as indicated by GPs $(n=126)$, of the POC troponin test in diagnosing acute coronary syndrome in primary care, as well as the aspects that they consider to be favorably affected by this test.

In general, GPs believe that benefits related to the use of POC troponin tests include: diagnostic certainty $(67.5 \%)$, time until diagnosis $(55.6 \%)$, patient safety $(42.1 \%)$, and reduced healthcare costs $(41.3 \%)$ (Table 2). Purposes for which GPs would use a POC troponin test (top four choices) are: to exclude ACS $(76.2 \%)$, for reassuring patients $(50.0 \%)$, to improve their consultation with the cardiologist (43.7\%), and to confirm ACS $(40.5 \%)$ (Additional file 3 ).

To investigate whether the availability of a POC troponin analyzer will increase the frequency at which troponin tests are performed, Figure $2 \mathrm{a}$ shows the estimated frequency at which GPs request laboratory troponin tests at a regular laboratory, while Figure $2 \mathrm{~b}$ shows the expected frequency of performing a POC troponin test assuming GPs would have access to a POC troponin analyzer in their general practice. A total of $46.3 \%$ of GPs estimate to never perform a laboratory troponin test in patients without suspicion of ACS. This probability is expected to decrease to $28.6 \%$ in case a POC troponin analyzer is available. Aggregating over the estimated frequencies of troponin use in Figure $2 \mathrm{a}$ and $2 \mathrm{~b}$, the probability that a troponin test is performed, in patients in whom the GP is uncertain about the presence of ACS, is $55.1 \%$ for POC tests, and $30.3 \%$ for laboratory tests. In patients strongly suspected of ACS, those probabilities are 26.3 and $4.9 \%$, respectively.

\section{Effect of POC troponin tests on GPs' referral decisions}

For the patient case which was designed to represent a patient with a low risk of ACS, the probability of ACS as estimated by the GPs was $11.2 \% \quad(\mathrm{CI}=9.0-13.5 \%)$. For the intermediate risk case this probability was estimated at $31.5 \%$ $(\mathrm{CI}=27.7-35.3 \%)$. In all, $80.2 \%$ of GPs estimated a higher probability of ACS in the intermediate risk case as compared with the low risk case. Figure 3 shows to what extent a discordant POC troponin test result is expected to make GPs revise their initial referral decision in both patient cases. In other words, this figure shows to what extent GPs indicated to change their initial referral decision in two hypothetical situations: (1) the GP initially decided to immediately refer the patient to the hospital, but the POC troponin level is then found to be negative, and (2) the GP initially decided not to refer the patient, but the troponin level is then found to be slightly, or even strongly elevated.

For the low and intermediate risk case, respectively 2.4 and $26.2 \%$ of GPs stated they would immediately refer the patient. Confronting those GPs with a non-elevated troponin level would make 66.7 and $81.8 \%$ to revise their decision in 
(a)

\section{Estimated frequency of using regular troponin tests in primary care} depending on the suspicion of ACS

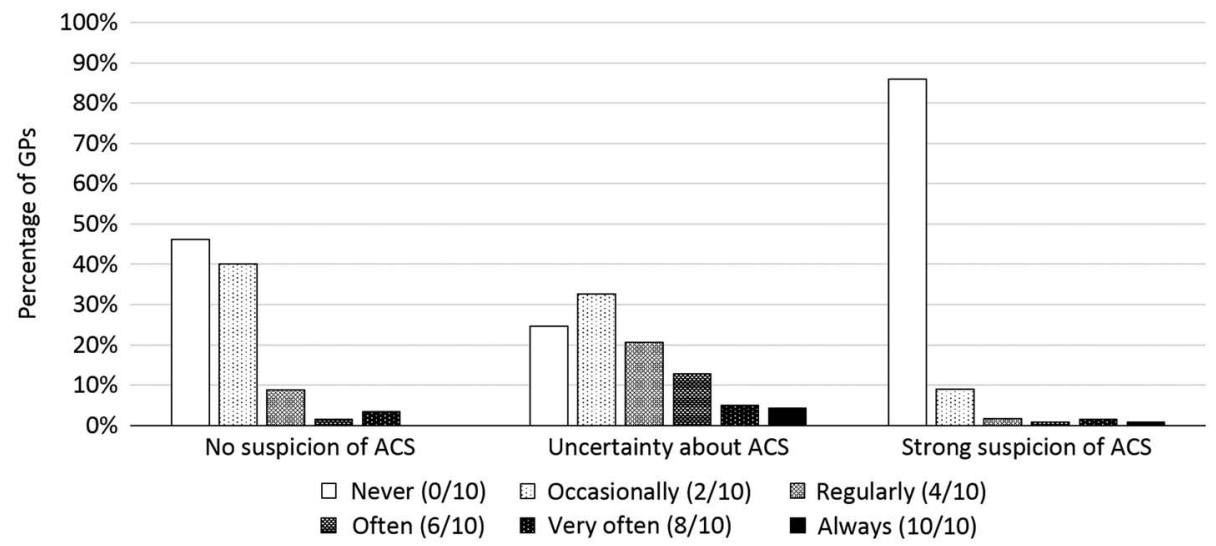

(b)

Expected frequency of using point-of-care troponin tests in primary care depending on the suspicion of ACS

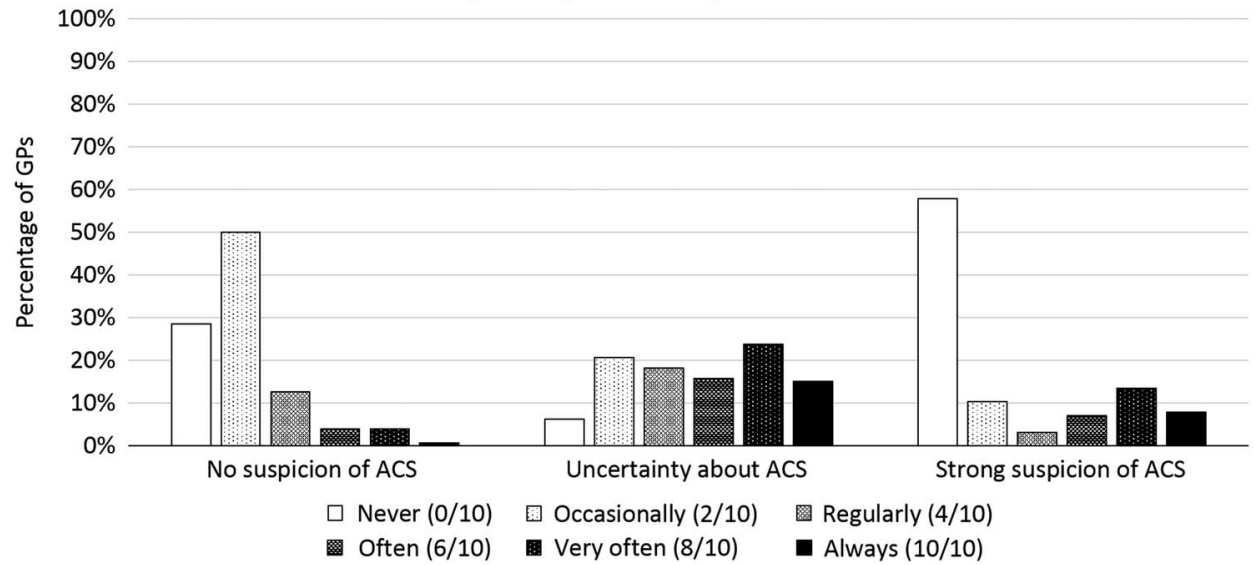

Figure 2 (a, b) (Expected) frequency of performing [point-of-care (POC)] troponin tests. This figure shows the (expected) frequency of performing troponin tests in a regular laboratory, and POC troponin tests in primary care, depending on the perceived suspicion of acute coronary syndrome (ACS).

the low and intermediate risk case, respectively. In contrast, in each case where the GP indicates not to refer immediately, presenting those GPs with a slightly elevated troponin level resulted in an immediately referral by 52.1 and $55.9 \%$. Of the remaining GPs who still indicate not to immediately refer, presenting them a strongly elevated troponin level resulted in an immediate referral by 70.7 and $58.5 \%$ in the low and intermediate risk case, respectively. Furthermore, GPs who decided not to immediately refer indicated that the availability of an elevated POC troponin test result would likely change that decision: there was a strong decrease in the number of GPs who indicated not to take further action or to perform additional examinations (eg, an electrocardiogram or additional laboratory tests), while there was a strong increase in the frequency at which they indicate to consult a cardiologist regarding this patient case. Furthermore, a $\chi^{2}$ test revealed that GPs' gut feeling (none, barely, or relatively much impact, as compared with high or very high

Primary Health Care Research \& Development 2017; 18: 386-397 


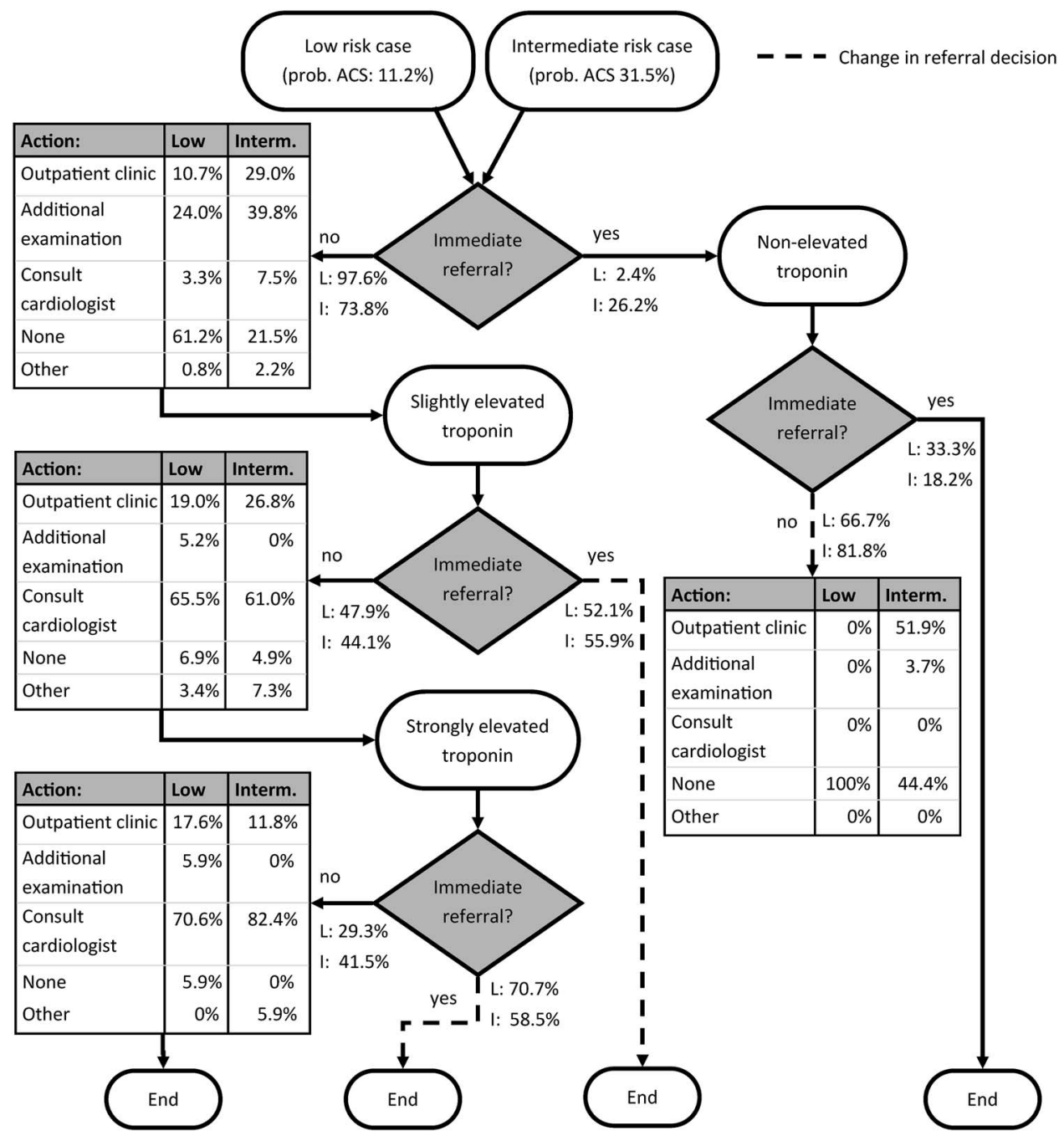

Figure 3 Impact of point-of-care (POC) troponin testing on GPs' referral decisions. The estimated probability of acute coronary syndrome (ACS) in the low and intermediate risk case was 11.2 and $31.5 \%$, respectively. To illustrate the flow of GPs through this figure, consider the example of $97.6 \%$ of all GPs who decide not to refer the low risk patient case based on a patient's signs, symptoms, medical history, medication use, and vital functions. The table that is presented describes the action taken (in \%) of those GPs who decided not to refer this patient. Next, all GPs who decided not to immediately refer were asked to additionally consider a slightly elevated POC troponin level, which could have been available for this patient during consultation. Based on this additional information, they were again asked if they would refer this patient immediately. In the low risk case, $47.9 \%$ of those GPs still decide not to refer this patient. When those remaining GPs were asked to consider a strongly elevated troponin level in this patient, which could have been available during consultation, $70.7 \%$ of those GPs indicate to immediately refer this low risk patient, while $29.3 \%$ still indicates not to refer this patient. ACS = acute coronary syndrome, prob. = probability.

impact) did not affect the probability of changing their immediate referral decision following a discordant POC troponin result (low-risk case: $P=0.56$, intermediate risk case: $P=0.86$ ).

\section{Requirements for an unobtrusive use of POC troponin tests}

In all, $78.3 \%$ of GPs consider 10 min the maximum acceptable duration of the POC troponin 
test, and only $4.8 \%$ find 20 min or longer acceptable. Also, $78.1 \%$ state that reimbursement of the POC device is necessary, while $68.9 \%$ demands the test can be performed with a finger prick instead of a venous blood sample.

\section{Discussion and conclusion}

GPs have a gatekeeping role in the healthcare system. Using diagnostic tests in primary care may improve GPs' ability to decide which patients to refer to secondary care, thereby improving quality of care provided, and preventing unnecessary costs and burden to patients. In particular, the availability of POC troponin tests may enhance GPs' ability to rule out ACS. The current study provides new insights into the potential impact of this test, as well as in factors that facilitate and impede implementation. Instead of focusing on test developers or policy makers in healthcare, our study explored the utility of troponin testing, and assessed how their referral behavior may change when POC troponin tests are implemented. Such information is required to understand and improve quality of care in primary care.

\section{Impact on referral decisions}

GPs have indicated that POC troponin results will change some of their referral decisions, indicating the tests' diagnostic utility. However, as the same two cases were presented to all GPs, the actual change may, of course, be different when other cases would be used. Also, GPs were provided with the POC troponin test result after making their initial referral decision, and this stepwise provision of information may have overemphasized the test result, and may thereby have artificially increased the impact of this test. However, as current POC troponin tests take $\geqslant 10 \mathrm{~min}$, it is likely that GPs already made an initial referral decision before having the test result available. As literature indicates that clinicians tend to cling to their initial diagnosis even when contradictory evidence becomes available (Rajkomar and Dhaliwal, 2011), it is unlikely that our approach led to a substantial overestimation of the potential effect of POC troponin testing in primary care.

Although GPs prefer a very sensitive POC test allowing rapid and accurate detection of ACS, the high-sensitive troponin tests currently used in laboratories increase the frequency at which slightly elevated troponin levels are encountered in patients who do not have an AMI (Thygesen et al., 2012). As our study indicates that a slightly elevated troponin may increase immediate referrals and consultations with cardiologists, this high-sensitivity may also increase healthcare costs.

As, according to the responding GPs, $54.9 \%$ of patients have $\geqslant 6 \mathrm{~h}$ complaints, the issue of the relatively low sensitivity of POC troponin very early after symptom onset will not apply to those patients. In addition, although this test is unlikely to be performed in patients with a high suspicion of ACS, GPs estimate that they only have a high suspicion in about half of the $26.8 \%$ of immediately referred patients. Thus, the POC troponin test might be of added value in a relatively large proportion of patients. In addition, as the referral decision after the POC troponin test was found to be independent from the estimated effect of gut feeling by GPs, POC troponin tests may improve GPs' ability to rule out ACS and thereby prevent referrals. Although this will decrease healthcare costs, the availability of a POC test might increase the frequency at which a patient's troponin level is measured, which is most likely explained by the shorter turn-around-time as compared with the laboratory test.

\section{Strengths and limitations}

A limitation of the current approach involves the risk of recall bias, as GPs are asked to make estimations concerning referral rates of chest pain patients and about the frequency with which they request laboratory troponin tests. Depending on the number of patients presenting with chest pain in the GP's office each month, which likely ranges from 2 to 4 , a recall period of 3 months would mean that GP's estimates are based on 6-12 patients. Given the relatively large number of respondents in the current study, and the absence of reasons why GPs would systematically underestimate or overestimate these numbers, it is likely that our overall results are realistic and robust. Although it might have been possible to additionally use primary care databases to gather more detailed information on current management of chest pain patients, such databases cannot provide insights in the potential use of POC troponin tests. Finally, more accurate data might also be obtained by 
performing a pragmatic trial. However, such a trial will be costly and time-consuming, and the chosen approach already allows deriving valuable estimates of intended POC troponin at low cost and in a short time period.

Although the number of respondents was relatively large (126 responses that could be included in the final analysis), the low response rate of $15.1 \%$ represents a limitation to our study. However, this issue of low response rates among GPs has been reported previously (Parkinson et al., 2015). To investigate the impact of this low response rate, results from our survey have been compared with the results of another recent Dutch survey study concerning POC tests in primary care (Cals et al., 2014). Results indicate that the availability of POC tests in Dutch general practices was very similar (Additional file 2). Compared to this previous study, only the availability of POC C-reactive protein (CRP) tests and glycated hemoglobin $\left(\mathrm{HbA}_{1 \mathrm{c}}\right)$ tests increased strongly, which can be explained by the increase in scientific evidence that has become available and the inclusion of the CRP POC test in the guideline 'Acute Cough' of the Dutch College of General Practitioners (Cals et al., 2009; 2011; Lenters-Westra and Slingerland, 2014; Verheij et al., 2011). In addition, we found that $67.1 \%$ of GPs perceive moderate to very high added value of POC troponin tests, whereas $65 \%$ of the GPs previously expressed their desire to use this test (Cals et al., 2014). These similar results were found despite the possible overrepresentation of GPs located in more rural areas in the Netherlands. Also, although the distance between general practices and hospitals, even in rural areas, is relatively low in the Netherlands as compared with other countries, the relation found between the perceived added value of the POC troponin test and the distance of the general practice from a hospital does corroborate previous findings in other countries (Howick et al., 2014). Consequently, the overall perceived added value of the POC troponin test by GPs across the Netherlands might be somewhat lower than reported here.

Previous research has shown that GPs in different countries unanimously expressed the desire to have this test available in their office (Howick et al., 2014). In addition, as issues of the aging population and the increased demand of healthcare usage are applicable to all (developed) countries, the results from this study performed in the Netherlands are expected to be generalizable to other countries.

\section{Recommendations}

As most currently available POC troponin tests do not yet meet GPs' requirements (Bingisser et al., 2012), designing a test that is fast and only requires a finger prick will be paramount to the implementation of POC troponin testing in Dutch primary care. Besides, reimbursement is considered crucial. Therefore, a few recommendations to enhance (efficient) implementation and use of POC troponin testing can be given. First, as the current study investigated the impact of only a few POC troponin levels on GPs' referral decisions, it is recommended to investigate this impact for multiple different troponin levels. Second, the two cases used in this study both concerned patients aged below 65 years. However, as previous research states that the use of different decision limits for high-sensitive troponin should be considered in elderly patients (Andersson et al., 2015), GPs' referral decisions may also be dependent upon the patient's age. Third, the prognostic value of slightly elevated troponin levels from increasingly sensitive tests to guide therapy may be investigated (Sherwood and Kristin Newby, 2014). Fourth, as research has shown that POC troponin tests may often be performed without prior ischemia assessment by the clinician (Ahmad et al., 2015), the introduction of (adapted) decision rules in primary care, like the MACS or HEART score developed for emergency care, might improve the correct triaging of chest pain patients and identify those that benefit most from additional POC troponin testing (Backus et al., 2013; Body et al., 2014).

Although the consideration to use POC troponin has to be made by each GP individually, this study gives insights in the barriers and facilitators regarding this implementation decision, and shows the expected impact when this test would be available in clinical practice. The findings presented in this study are thus not only relevant for GPs, but also for policy makers, as well as for developers of POC testing technology. In addition, previous research has indicated that a POC troponin test may be cost saving (by reducing emergency hospital referrals), although this may come at the expense of missed cases of ACS (Nilsson et al., 2013; 2014). However, despite those 
valuable insights, those studies were limited by a non-randomized design and a small number of AMI patients. Further research is therefore recommended to synthesize evidence on the frequency of POC troponin testing, the impact on (correct and incorrect) referral decisions, test costs, and the benefits from rapid and adequate treatment in a formal cost-effectiveness analysis.

In conclusion, although the findings of the current study indicate that the POC troponin test may be of added value for excluding ACS in patients considered at low or intermediate risk, as well as to reassure patients, improvements in its diagnostic performance are still needed to ensure their implementation. Despite the fact that most of the currently available POC troponin tests do not yet meet the GPs' requirements, ongoing developments are likely to increase the test's expected benefits. The insight obtained from this study can be used to guide further development, as well as to facilitate implementation of the POC troponin test in clinical practice.

\section{Acknowledgments}

The authors thank all GPs for their participation in this questionnaire.

\section{Financial Support}

This research received no specific grant from any funding agency, commercial, or not-for-profit sectors.

\section{Conflicts of Interest}

None.

\section{Supplementary material}

To view supplementary material for this article, please visit http://dx.doi.org/10.1017/S1463423617000135

\section{References}

Ahmad, F.A., Dobbin, S. and Hargreaves, A.D. 2015: Implementation of point-of-care troponin $\mathrm{T}$ testing in clinical practice. British Journal of Cardiology, 22.

Andersson, P.O., Karlsson, J.E., Landberg, E., Festin, K. and Nilsson, S. 2015: Consequences of high-sensitivity troponin
T testing applied in a primary care population with chest pain compared with a commercially available point-of-care troponin $\mathrm{T}$ analysis: an observational prospective study. BMC Research Notes 8, 210.

Authors/Task Force Members, Roffi, M., Patrono, C., Collet, J.P., Mueller, C., Valgimigli, M., Andreotti, F., Bax, J.J., Borger, M.A., Brotons, C., Chew, D.P., Gencer, B., Hasenfuss, G., Kjeldsen, K., Lancellotti, P., Landmesser, U., Mehilli, J., Mukherjee, D., Storey, R.F. and Windecker, S. 2015: 2015 ESC Guidelines for the management of acute coronary syndromes in patients presenting without persistent ST-segment elevation: Task Force for the Management of Acute Coronary Syndromes in Patients Presenting without Persistent ST-Segment Elevation of the European Society of Cardiology (ESC). European Heart Journal 37, 267-315.

Backus, B.E., Six, A.J., Kelder, J.C., Bosschaert, M.A., Mast, E.G., Mosterd, A., Veldkamp, R.F., Wardeh, A.J., Tio, R., Braam, R., Monnink, S.H., van Tooren, R., Mast, T.P., van den Akker, F., Cramer, M.J., Poldervaart, J.M., Hoes, A.W. and Doevendans, P.A. 2013: A prospective validation of the HEART score for chest pain patients at the emergency department. International Journal of Cardiology 168, 2153-58.

Bingisser, R., Cairns, C., Christ, M., Hausfater, P., Lindahl, B., Mair, J., Panteghini, M., Price, C. and Venge, P. 2012: Cardiac troponin: a critical review of the case for point-ofcare testing in the ED. American Journal of Emergency Medicine 30, 1639-49.

Body, R., Carley, S., Mcdowell, G., Pemberton, P., Burrows, G., Cook, G., Lewis, P.S., Smith, A. and Mackway-Jones, K. 2014: The Manchester Acute Coronary Syndromes (MACS) decision rule for suspected cardiac chest pain: derivation and external validation. Heart 100, 1462-68.

Bosner, S., Becker, A., Haasenritter, J., Abu Hani, M., Keller, H., Sonnichsen, A.C., Karatolios, K., Schaefer, J.R., Seitz, G., Baum, E. and Donner-Banzhoff, N. 2009: Chest pain in primary care: epidemiology and pre-work-up probabilities. European Journal of General Practice 15, 141-46.

Bruins Slot, M.H., van der Heijden, G.J., Stelpstra, S.D., Hoes, A.W. and Rutten, F.H. 2013: Point-of-care tests in suspected acute myocardial infarction: a systematic review. International Journal of Cardiology 168, 5355-62.

Bruyninckx, R., Aertgeerts, B., Bruyninckx, P. and Buntinx, F. 2008: Signs and symptoms in diagnosing acute myocardial infarction and acute coronary syndrome: a diagnostic metaanalysis. British Journal General Practice 58, 105-11.

Buntinx, F., Knockaert, D., Bruyninckx, R., de Blaey, N., Aerts, M., Knottnerus, J.A. and Delooz, H. 2001: Chest pain in general practice or in the hospital emergency department: is it the same? Family Practice 18, 586-89.

Cals, J.W., Ament, A.J., Hood, K., Butler, C.C., Hopstaken, R.M., Wassink, G.F. and Dinant, G.J. 2011: C-reactive protein point of care testing and physician communication skills training for lower respiratory tract infections in general practice: economic evaluation of a cluster randomized trial. Journal of Evaluation in Clinical Practice 17, 1059-69. 
Cals, J.W., Butler, C.C., Hopstaken, R.M., Hood, K. and Dinant, G.J. 2009: Effect of point of care testing for C reactive protein and training in communication skills on antibiotic use in lower respiratory tract infections: cluster randomised trial. British Medical Journal 338, b1374.

Cals, J.W.L., Schols, A.M.R., van Weert, H.C.P.M., Stevens, F., Zeijen, C.G.I.P., Holtman, G., Lucassen, W.A.M. and Berger, M.Y. 2014: Sneltesten in de huisartsenpraktijk: huidig gebruik en behoefte aan testen in de toekomst. Nederlands Tijdschrift Voor Geneeskunde 158, 7.

Dutch College of General Practitioners. 2012: NHG-Standaard Acuut coronair syndroom (eerste herziening) [Online]. Retrieved 2 August 2016 from https://www.nhg.org/stan daarden/volledig/nhg-standaard-acuut-coronair-syndroom-eerste herziening\#note-13.

Howick, J., Cals, J.W., Jones, C., Price, C.P., Pluddemann, A., Heneghan, C., Berger, M.Y., Buntinx, F., Hickner, J., Pace, W., Badrick, T., van den Bruel, A., Laurence, C., van Weert, H.C., van Severen, E., Parrella, A. and Thompson, M. 2014: Current and future use of point-of-care tests in primary care: an international survey in Australia, Belgium, The Netherlands, the UK and the USA. BMJ Open 4, e005611.

Lenters-Westra, E. and Slingerland, R.J. 2014: Three of 7 hemoglobin A1c point-of-care instruments do not meet generally accepted analytical performance criteria. Clinical Chemistry 60, 1062-72.

Limesurvey Project Team/Schmitz, C. 2015. LimeSurvey: an open source survey tool. Hamburg, Germany: LimeSurvey Project.

Marshall, G.A., Wijeratne, N.G. and Thomas, D. 2014: Should general practitioners order troponin tests? Medical Journal of Australia 201, 155-57.

Nilsson, S., Andersson, A., Janzon, M., Karlsson, J.E. and Levin, L.A. 2014: Cost consequences of point-of-care troponin T testing in a Swedish primary health care setting. Scandinavian Journal of Primary Health Care 32, 241-47.

Nilsson, S., Andersson, P.O., Borgquist, L., Grodzinsky, E., Janzon, M., Kvick, M., Landberg, E., Nilsson, H. and Karlsson, J. E. 2013: Point-of-care troponin T testing in the management of patients with chest pain in the Swedish primary care. International Journal of Family Medicine, 2013, 532093.

Nilsson, S., Scheike, M., Engblom, D., Karlsson, L.G., Molstad, S., Akerlind, I., Ortoft, K. and Nylander, E. 2003: Chest pain and ischaemic heart disease in primary care. British Journal of General Practice 53, 378-82.

Okkes, I.M., Oskam, S.K., van Boven, K. and Lamberts, H. 2005: Continue morbiditeitsregistratie Nijmegen. Episodes of care in family practice. Epimiological data based on the routine use of the International Classification of Primary Care (ICPC) in the Transition project of the Academic Medical Center/University of Amsterdam (1985-2003). Amsterdam: Academic Medical Center/University of Amsterdam, Department of Family Medicine.

Parkinson, A., Jorm, L., Douglas, K.A., Gee, A., Sargent, G.M., Lujic, S. and Mcrae, I.S. 2015: Recruiting general

Primary Health Care Research \& Development 2017; 18: 386-397 practitioners for surveys: reflections on the difficulties and some lessons learned. Australian Journal of Primary Health 21, 254-58.

Philips In-vitro Diagnostics. 2016: Minicare I-20, Enabling near patient blood testing in the acute care setting [Online]. Retrieved April 21, 2016, from http://www.philips.n1/healthcare/product/HCNOCTN496/minicare-i20-enabling-nearpatient-blood-testing-in-the-acute-care-setting.

R Core Team 2015. $R$ : A languange and environment for statistical computing. Vienna, Austria: R Foundation for Statistical Computing.

Rajkomar, A. and Dhaliwal, G. 2011: Improving diagnostic reasoning to improve patient safety. The Permanente Journal 15, 68-73.

Ruigomez, A., Rodriguez, L.A., Wallander, M.A., Johansson, S. and Jones, R. 2006: Chest pain in general practice: incidence, comorbidity and mortality. Family Practice 23, 167-74.

Rutten, F.H., Bakx, J.C., Bruins Slot, M.H.E., van Casteren, B.C.A.M., Derks, C.J.T., Rambharose, V.R., Burgers, J.S., Wiersma, T.J., Mensink, P.A.J.S. and Bouma, M. 2012: NHG-standaard acuut coronair syndroom (eerste herziening). Huisarts en Wetenschap 55, 564-70.

Sherwood, M.W. and Kristin Newby, L. 2014: High-sensitivity troponin assays: evidence, indications, and reasonable use. Journal of American Heart Association 3, e000403.

Thygesen, K., Alpert, J.S., Jaffe, A.S., Simoons, M.L., Chaitman, B.R. and White, H.D., Joint ESC/ACCF/AHA/WHF Task Force for the Universal Definition of Myocardial Infarction, Katus, H.A., Lindahl, B., Morrow, D.A., Clemmensen, P.M., Johanson, P., Hod, H., Underwood, R., Bax, J.J., Bonow, R.O., Pinto, F., Gibbons, R.J., Fox, K.A., Atar, D., Newby, L.K., Galvani, M., Hamm, C.W., Uretsky, B.F., Steg, P.G., Wijns, W., Bassand, J.P., Menasche, P., Ravkilde, J., Ohman, E.M., Antman, E.M., Wallentin, L.C., Armstrong, P.W., Simoons, M.L., Januzzi, J.L., Nieminen, M.S., Gheorghiade, M., Filippatos, G., Luepker, R.V., Fortmann, S.P., Rosamond, W.D., Levy, D., Wood, D., Smith, S.C., Hu, D., Lopez-Sendon, J.L., Robertson, R.M., Weaver, D., Tendera, M., Bove, A.A., Parkhomenko, A.N., Vasilieva, E.J. and Mendis, S. 2012: Third universal definition of myocardial infarction. Circulation 126, 2020-35.

Tomonaga, Y., Gutzwiller, F., Luscher, T.F., Riesen, W.F., Hug, M., Diemand, A., Schwenkglenks, M. and Szucs, T.D. 2011: Diagnostic accuracy of point-of-care testing for acute coronary syndromes, heart failure and thromboembolic events in primary care: a cluster-randomised controlled trial. BMC Family Practice 12, 12.

van Buuren, S. and Groothuis-Oudshoorn, K. 2011: mice: Multivariate imputation by chained equations in R. Journal of Statistical Software 45, 1-67.

van der Heijden, G.J., Donders, A.R., Stijnen, T. and Moons, K.G. 2006: Imputation of missing values is superior to complete case analysis and the missing-indicator method in multivariable diagnostic research: a clinical example. Journal of Clinical Epidemiology 59, 1102-09. 
van Hassel, D.T.P., Kasteleijn, A. and Kenens, R.J. 2015. Cijfers uit de registratie van huisartsen - peiling 2014. Utrecht: NIVEL.

Verheij, T.J.M., Hopstaken, R.M., Prins, J.M., Salomé, P.L., Bindels, P.J., Ponsioen, B.P., Sachs, A.P.E., Thiadens, H.A. and Verlee, E. 2011: NHG-Standaard Acuut hoesten (Eerste herziening). Huisarts en Wetenschap 54, 68-92.
Wiener, J.M. and Tilly, J. 2002: Population ageing in the United States of America: implications for public programmes. International Journal of Epidemiology 31, 776-81.

World Health Organization 2016. World Health Statistics: monitoring health for the SDGs, sustainable development goals. Geneva: World Health Organization. 